\title{
Molecular Structure of Human Transferrin - Transferrin Receptor Complex
}

\author{
Viroj Wiwanitkit \\ Department of Laboratory Medicine, Faculty of Medicine, Chulalongkorn University, Bangkok \\ Thailand 10330; E-mail: wviroj@yahoo.com
}

Received: 19 May 2006 / Accepted: 14 June 2006 / Published: 24 July 2006

\begin{abstract}
Transferrin receptor (TfR) is a glycoprotein mediating the entry of ferric transferrin (Tf) from the extracellular compartment into the cells. TfR are present on the surface of many cell types but they are most abundant on cells active in hemoglobin synthesis. However, the knowledge on the complex, recombination, between Tf and sTfR is limited. Here, the author performs an analysis to study the molecular structure of human Tf - sTfR complex. The output 3D molecular structure from the combination between Tf and TfR is derived. The property as well as geometry of the derived complex was also presented.
\end{abstract}

Keywords: transferrin, receptor, complex, structure

\section{Introduction}

Transferrin receptor (TfR) [1-3] is a glycoprotein mediating the entry of ferric transferrin (Tf) from the extracellular compartment into the cells. TfR are present on the surface of many cell types but they are most abundant on cells active in hemoglobin synthesis [1-3]. Up-regulation of the expression of cellular TfR occurs as a result of an inadequate tissue supply of iron or increased cellular demand for iron, therefore, elevation of soluble form of TfR (sTfR) can be detected in the context of iron deficiency anemia, thalassemia and polycythemia. Presently, the determination of sTfR becomes a widely used tool for measuring erythropoiesis [1-3], but most tests are mainly restricted to research laboratory settings. At present, plasma concentrations of the receptor reflect cellular receptor numbers and may be determined by enzyme immunoassay on automated analyzer [4]. Recently, Bhokaisawan $e t$ $a l$ studied the diagnostic value of sTfR and they found that sTfR could be used as an alternative test for monitoring of erythropoiesis [5]. For present clinical application, sTfR can be used to study erythropoiesis in situations in which ferrokinetics is not acceptable such as pregnancy [6]. Also, sTfR 
is particularly useful for serial studies such as for monitoring the recovery of erythropoiesis after stem cell transplantation or after treatment with erythropoietin [6].

The structures of both Tf and TfR have been studied and documented for a few recent years. However, the knowledge on the complex, recombination, between Tf and sTfR is limited. Here, the author performs an analysis to study the molecular structure of human Tf - sTfR complex. To reach the target, a computer-based study for in silico protein recombination modeling is performed.

\section{Results and Discussion}

The output 3D molecular structure from the combination between $\mathrm{Tf}$ and $\mathrm{TfR}$ is derived (Figure 1). Using Swiss-Pdb Viewer, the most appropriate modeling templates for this model is presented in Figure 2. Concerning the properties of the derived complex, $\mathrm{H}$ bond, molecular surface, electrostatic potential patterns of the complex were shown in Figure 3. Concerning the geometry of the derived complex, the shape-parameters as X-axis = 63.3 Angstrom, Y-axis = 83.3 Angstrom and Z-axis = 46.6 Angstrom can be derived.

Figure 1. 3D molecular structure from the combination between $\mathrm{Tf}$ and TfR.

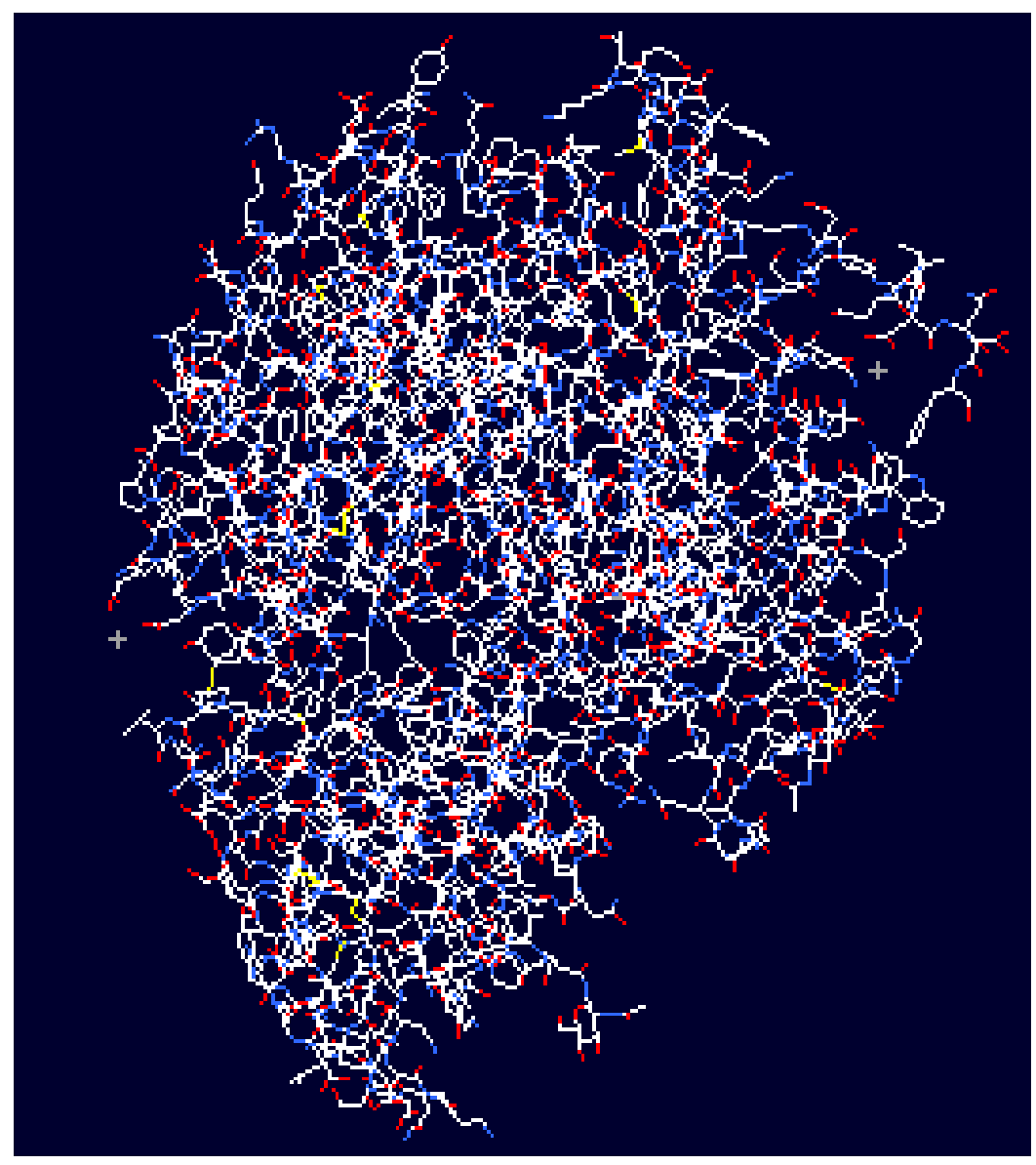

*The default atoms colors are the following: $\mathrm{C}=$ white, $\mathrm{O}=$ red, $\mathrm{N}=$ blue, $\mathrm{S}=$ yellow, $\mathrm{P}=$ orange, $\mathrm{H}=$ cyan, other = gray 
Figure 2. The most appropriate modeling templates for the derived Tf-TfR complex model.

LYWDDLKRKLSEKLDSTDFTSTIKLLNENSYVPREAGSQKDENLALYVENEFREFKLSKVWRDQHFVK IQVKDSAQNSVIIVDKNGRLVYLVENPGGYVAYSKAATVTGKLVHANFGTKKDFEDLYTPVNGSIVIV RAGKITFAEKVANAESLNAIGVLIYMDQTKFPIVNAELSFFGHAHLGTGDPYTPGFPSFNHTQFPPSRSS GLPNIPVQTISRAAAEKLFGNMEGDCPSDWKTDSTCRMVTSESKTYKELIERIPELNKVARAAAEVAGQ FVIKLTHDVELNLDYEEYNSQLLSFVRDLNQYRADIKEMGLSLQWLYSARGDFFRATSRLTTDFGNAN VKLTVSNVLKEIKILNIFGVIKGFVEPDHYVVVGAQRDAWGPGAAKSGVGTALLLKLAQMFSDMVLK DGFQPSRSIIFASWSAGDFGSVGATEWLEGYLSSLHLKAFTYINLDKAVLGTSNFKVSASPLLYTLIEKT MQNVKHPVTGQFLYQDSNWASKVEKLTLDNAAFPFLAYSGIPAVSFCFCEDTDYPYLGTTMDEKTDR FVMKKLNDRVMRVEYHFLSPYVSPKESPFRHVFWGSGSHTLPALLENLKLRKQNNGAFNETLFRNQL ALATWTIQGAANALSGDVWDIDNEF

Figure 3. Some properties of the derived Tf-TfR complex.

A. $\mathrm{H}$ bond pattern (in green)

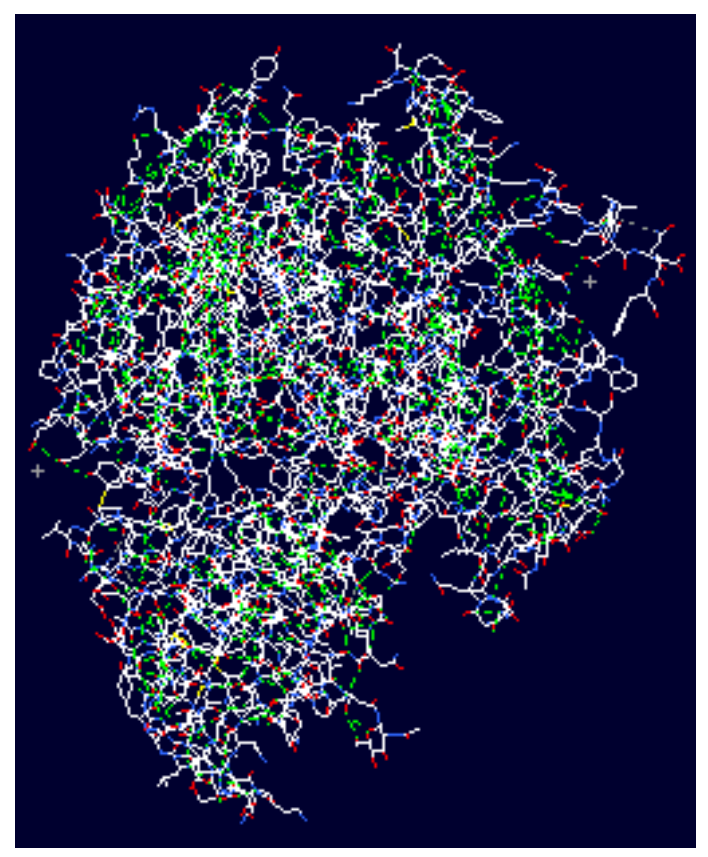


B. Molecular surface pattern (positive potentials are drawn in blue, negative in red)

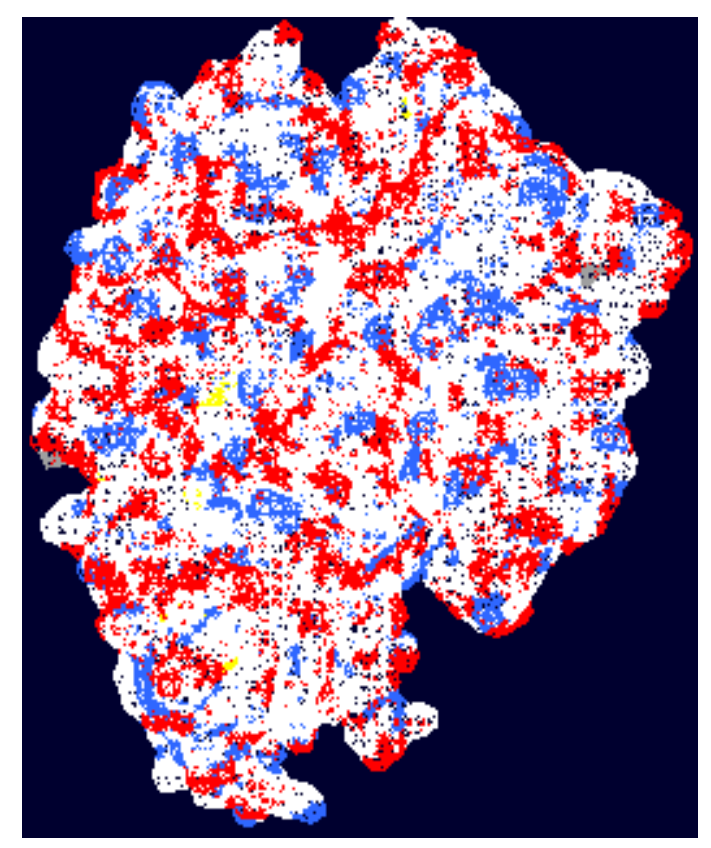

C. Electrostatic potential pattern (positive potentials are drawn in blue, negative in red)

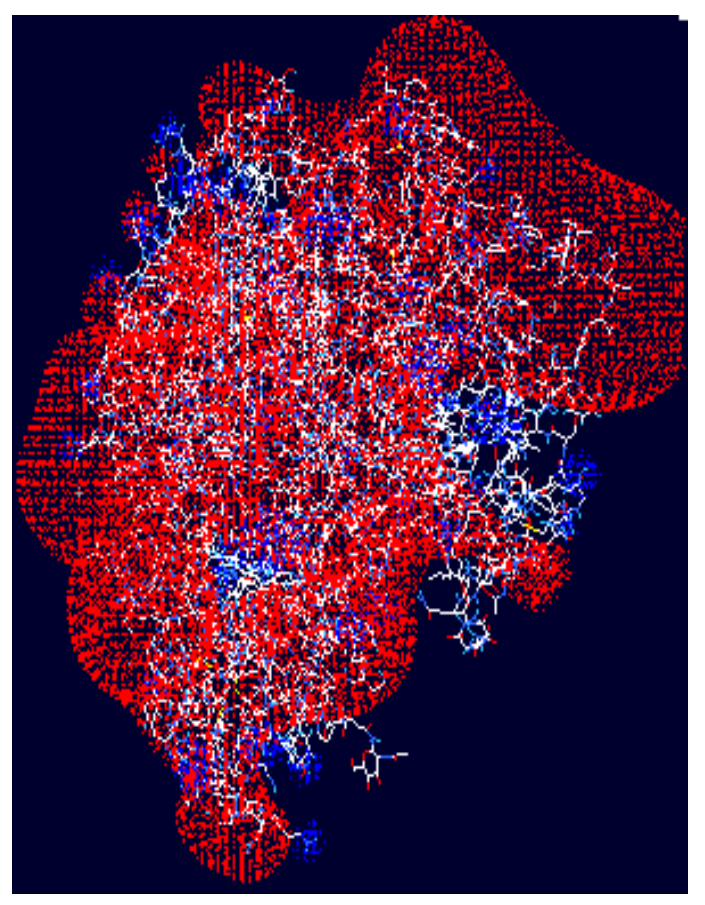

\footnotetext{
* Figure 3 Notes
}

$1 \mathrm{H}$-bonds are detected on the basis of distance, atom type and angle. H-bonds are detected if an $\mathrm{H}$ is in a 1.2 up to $2.76 \mathrm{~A}$ range of a "compatible" donor atom.

2.The electrostatic potential of proteins - caused by charged side chains and bound ions - plays a role e.g in protein folding and stability, enzyme catalysis or specific protein-protein recognition. In general, electrostatic potentials are visualized as molecular surface pattern (B) or electrostatic pattern (C). 
Tf was discovered more than half a century ago, however, the discovery of TfR was just in the past two decades. Considering human iron metabolism, most cells acquire iron from plasma Tf and it is the TfR that is responsible for the internalization of transferrin-bound iron and its subsequent intracellular release [4]. Not only the carrying of iron, TfRs have also shown potentials in delivery of therapeutic drugs or genes into the brain across blood-brain barrier [7]. Due to the recent advance in molecular biology, the molecular structures of Tf and TfR have been widely studied. However, further structural and functional analyses on the recombination between the Tf and TfR are warranted for better understanding on the Tf-related mechanism [8]. Although much is understood of the Tf endocytotic cycle, little has been uncovered of the molecular details underlying the formation of the Tf-TfR complex [9]. Studying on the structures of TfR alone and complexed with $\mathrm{Tf}$ at subnanometer resolution provides a clue for the mechanism for communicating binding events between TfR chains and sheds light upon the function of Tf in regulating iron homeostasis [8-9].

Here, the author uses a computation protein-ligand technology to model the 3D structure of the TfTfR complex. The properties of the complex including $\mathrm{H}$ bond, molecular surface and electrostatic potential were analyzed. The geometry of the complex was also evaluated. The derived shapeparameters in this study are concordant with the previous cryoelectron microscopy findings by Cheng et al [9]. However, there is no analysis of the properties of the complex in that study. The derived model in this study can be applied for further study on local structural changing, which can be introduced by amino acid mutation. In addition, it can be served as the basis for other proteinrecombinants production.

\section{Experimental Section}

The database namely RCSB PDB Protein Databank [10] was used for data mining of the molecular structure for human Tf and sTfR. RCSB PDB Protein Databank is accepted as an information portal to biological macromolecular structures [10]. Concerning the search strategy, the keyword "TRANSFERIN" was used. The human Tf and TfR were selected. Then a computational molecular technique, PatchDock [11], was used for modeling of the recombination. Briefly, PatchDock is a computational molecular technique for molecular docking based on shape complementarity principle [11]. The input is two molecules of any type: proteins, DNA, peptides, drugs [6]. In this study, the two input molecules are Tf (PDB code, 1D4N chain A) and TfR (PDB code, 1CX8 chain A). The output is a potential complex sorted by shape complementarity criteria [11]. The output or result was further process to be in the format of three - dimension (3D) molecular structure by Swiss-Pdb Viewer (GlaxoSmithKline R\&D \& the Swiss Institute of Bioinformatics). Then Swiss-Pdb Viewer was used for geometrical analysis of the derived Tf-TfR complex. Also Swiss-Pdb Viewer was used for analyses of other additional properties including $\mathrm{H}$ bond, molecular surface, electrostatic potential patterns of the complex. The simplified schematic diagram showing the experimental steps in this study is presented in Figure 4. 
Figure 4. Simplified schematic diagram showing the experimental steps.

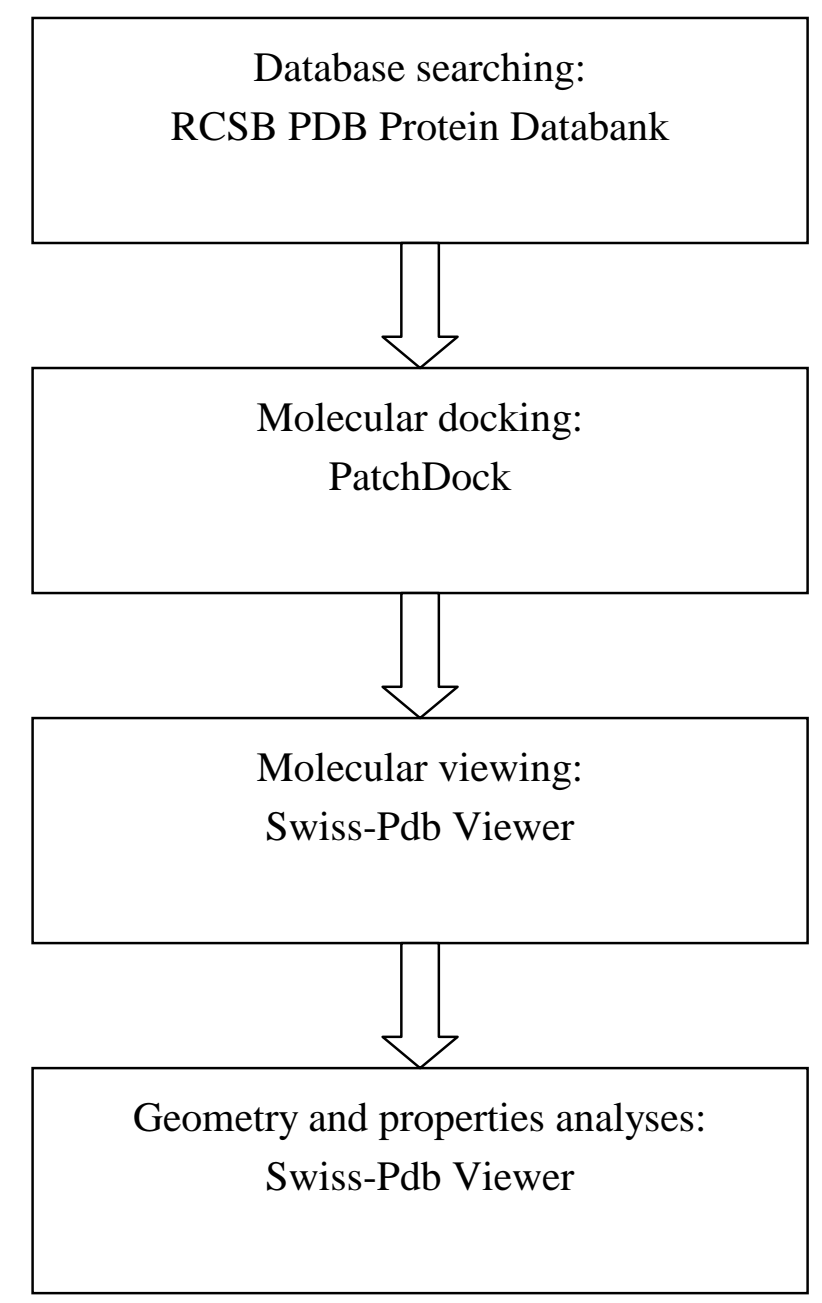

\section{References}

1. Suominen, P.; Punnonen, K.; Rajamäki, A.; Irjala, K. Serum transferrin receptor and transferrin receptor-ferritin index identify healthy subjects with subclinical iron deficits. Blood 1998, 92, 2934-2939

2. Ahluwalia, N.; Lammi-Keefe, C.J.; Haley, N.R.; Beard, J.L. Day-to-day variation in iron-status indexes in elderly women. Am. J. Clin. Nutr. 1993, 57, 414-419

3. Cooper, M.J.; Zlotkin, S.H. Day-to-day variation of transferrin receptor and ferritin in healthy men and women. Am. J. Clin. Nutr. 1996, 64, 738-742

4. Bhokaisawan, N.; Paritpokee, N.; Wiwanitkit, V.; Boonchalermvichian, C.; Nuchprayoon, I. Serum concentrations of soluble transferrin receptor among paediatric patients with transfusion-dependant beta-thalassaemia/haemoglobin E. Ann. Trop. Med. Parasitol. 2002, 96, 427-429

5. Fillet, G.; Beguin, Y. Monitoring of erythropoiesis by the serum transferrin receptor and erythropoietin. Acta. Clin. Belg. 2001, 56, 146-54 
6. Worwood, M. Serum transferrin receptor assays and their application. Ann. Clin. Biochem. 2002, $39,221-30$

7. Li, H.; Qian, Z.M. Transferrin/transferrin receptor-mediated drug delivery. Med. Res. Rev. 2002, 22, 225-250

8. Bennett, M.J.; Lebron, J.A.; Bjorkman, P.J. Crystal structure of the hereditary haemochromatosis protein HFE complexed with transferrin receptor. Nature 2000, 403, 46-53

9. Cheng, Y.; Zak, O.; Aisen, P.; Harrison, S.C.;Walz, T. Structure of the human transferrin receptortransferrin complex. Cell 2004, 116, 565-576

10. Berman, H.M.; Westbrook, J.; Feng, Z.; Gilliland, G.; Bhat, T.N.; Weissig, H.; Shindyalov, I.N.; Bourne, P.E. The Protein Data Bank. Nucleic. Acids. Research 2000, 28, 235-242

11. Schneidman-Duhovny, D.; Inbar, Y.; Polak, V.; Shatsky, M.; Halperin, I.; Benyamini, H.; Barzilai, A.; Dror, O.; Haspel, N.; Nussinov, R.; Wolfson, H.J. Taking geometry to its edge: fast unbound rigid (and hinge-bent) docking. Proteins 2003, 52, 107-112

(C) 2006 by MDPI (http://www.mdpi.org). Reproduction is permitted for noncommercial purposes. 